\title{
COMPARISON OF PROPOFOL AND THIOPENTONE AS INDUCTION AGENTS FOR MODIFIED ELECTROCONVULSIVE THERAPY
}

\author{
Mukesh Mukundan ${ }^{1}$, Syed Fazal Mahmood ${ }^{2}$, S Padmanabha ${ }^{3}$ \\ ${ }_{1}^{1}$ Post Graduate Trainee, Department of Anaesthesiology, Yenepoya Medical College, Mangalore. \\ ${ }^{2}$ Post Graduate Trainee, Department of Anaesthesiology, Yenepoya Medical College, Mangalore. \\ ${ }^{3}$ Professor and HOD, Department of Anaesthesiology, Yenepoya Medical College, Mangalore.
}

\begin{abstract}
The aim of the study was to compare the seizure duration, haemodynamic changes and recovery characteristics following modified electro convulsive therapy (ECT) between propofol and thiopentone, used as anaesthetic agents. Forty patients who presented for a minimum of two ECT treatments consecutively were studied. Patients were randomly allocated to receive either $1 \%$ propofol or $2.5 \%$ thiopentone for their first treatment and the other drug was administered on the second occasion. All patients were preoxygenated for three minutes. Isolation of a limb was done in the upper limb at the level of the arm by using a blood pressure cuff that was inflated $50 \mathrm{mmHg}$ above systolic blood pressure. Anaesthesia was induced. Following the onset of anaesthetic effect, depolarizing muscle relaxant succinyl choline was administered intravenously. Muscle fasiculations or fine twitching movements monitored. The electrical stimulus was delivered by the attending psychiatrist using bifrontal electrodes. The duration of motor seizure in isolated limb was recorded. Thus concluding propofol is better induction agent than thiopentone sodium for modified electroconvulsive therapy.
\end{abstract}

KEYWORDS: Electroconvulsive Therapy, Propofol,Thiopentone Sodium.

HOW TO CITE THIS ARTICLE: Mukesh Mukundan, Syed Fazal Mahmood, S Padmanabha. "Comparison of Propofol and Thiopentone as Induction Agents for Modified Electroconvulsive Therapy." Journal of Evolution of Medical and Dental Sciences 2015; Vol. 4, Issue 94, November 23; Page: 15943-15946, DOI: 10.14260/jemds/2015/2322.

INTRODUCTION: Ever since its discovery, Electroconvulsive Therapy (ECT) has continued to occupy a central place in the armamentarium of psychiatrists inspite of advances in psychopharmaco therapy. ${ }^{1}$ Despite both medical and legal opposition it is still widely practiced as one of the cheapest, safest and yet one of the most effective therapeutic technique in the whole of medical sciences. ${ }^{2}$ Due to trauma caused to the patient physically and psychologically with unmodified direct electroconvulsive therapy in the past it has now been modified with anaesthesia. The aim of ECT is to produce a grand mal seizure. It is the seizure rather than the electrical stimulus, which is responsible for the therapeutic effect.

Electroconvulsive therapy can produce severe disturbances in the cardiovascular system, most commonly a transient period of hypertension and changes in the heart rate. ${ }^{3}$ These cardiovascular changes may be altered by using various anaesthetic drugs and the violent muscular contractions occurring during the convulsions can be reduced by the usage of muscle relaxants.

METHODOLOGY: After obtaining clearance from the institutional ethics committee, patients of either gender scheduled for modified electroconvulsive therapy (MECT) were selected for the study.

Financial or Other, Competing Interest: None.

Submission 28-10-2015, Peer Review 29-10-2015,

Acceptance 13-11-2015, Published 21-11-2015.

Corresponding Author:

Dr. Syed Fazal Mahmood,

Department of Anaesthesia,

Yenepoya Medical College, Mangalore-575018.

E-mail: lazaf4u@gmail.com

DOI:10.14260/jemds/2015/2322.
Patients with ASA physical status 1 or 2 and age between 16-60 years are included in the study. Patients in whom thiopentone sodium, propofol or succinylcholine were contraindicated and with renal, hepatic or neuromuscular disorders were excluded.

Forty patients who presented for a minimum of two ECT treatments consecutively were studied. Patients were randomly allocated to receive either $1 \%$ propofol or $2.5 \%$ thiopentone for their first treatment and the other drug was administered on the second occasion. Heart rate was monitored by palpating pulse beats (Radiation pulsation) and blood pressure was measured using a mercury sphygmomanometer at time intervals that have been indicated. Isolation of a limb was done in the upper limb at the level of the arm by using a blood pressure cuff that was inflated $50 \mathrm{mmHg}$ above systolic blood pressure.

Anaesthesia was induced by using either $1 \%$ propofol $(1.5 \mathrm{mg} / \mathrm{kg})$ or $2.5 \%$ thiopentone $(3 \mathrm{mg} / \mathrm{kg})$, given over 20 seconds through a $20 \mathrm{G}$ or 22 G I.V. cannulae.

The induction dose was considered adequate if the eyelash reflex was lost after 30seconds, following thiopentone or there was no response to call following propofol.

Additional dose of the appropriate agent was titrated as necessary. Following the onset of anaesthetic effect, depolarizing muscle relaxant succinyl choline $(0.5 \mathrm{mg} / \mathrm{kg})$ was administered. Muscle fasiculations or fine twitching movements inhibited its action.

The disappearance of these movements indicated that the maximal relaxation has occurred. The electrical stimulus was delivered by the attending psychiatrist using bifrontal electrodes.

The duration of motor seizure was recorded as the time taken from the administration of the electrical stimulus to the cessation of the tonic-clonic activity in the isolated limb. 
Arterial blood pressure and heart rate were recorded before and immediately after the injection of anaesthetic and then every one minute for the first five minutes following the electro shock. The time taken to follow simple commands (i.e., mentioning name on command or moving limbs to command) was recorded.

RESULTS: In this study, modified ECT was given to 40 patients who received alternately either propofol $(1.5 \mathrm{mg} / \mathrm{kg})$ or thiopentone $(3 \mathrm{mg} / \mathrm{kg})$ and the results evaluated. The dose of the drugs were titrated according to requirements. The mean dose of thiopentone (Group-I) used was $3.15 \mathrm{mg} / \mathrm{kg}$ and that for propofol (Group - II) was $1.56 \mathrm{mg} / \mathrm{kg}$.

ECT was given to patients with different age groups, weight and different psychiatric illness.

\begin{tabular}{|c|c|}
\hline Diagnosis & $\begin{array}{c}\text { No. of } \\
\text { Patients }\end{array}$ \\
\hline Mania & 1 \\
\hline Obsessive compulsive disorder & 1 \\
\hline Bipolar mood disorder & 3 \\
\hline Acute psychosis & 4 \\
\hline Post partum psychosis & 4 \\
\hline Paranoid schizophrenia & 4 \\
\hline Catatonia & 5 \\
\hline Schizophrenia & 6 \\
\hline Severe depression & 6 \\
\hline Maniac depressive disorders & 6 \\
\hline TOTAL & $\mathbf{4 0}$ \\
\hline \multicolumn{2}{|c|}{ Table 1: Diagnosis } \\
\hline
\end{tabular}

The percentage changes in Systolic blood pressure, Diastolic blood pressure and Heart rate from the baseline were calculated at various time intervals following delivery of shock.

\begin{tabular}{|c|c|c|c|}
\hline & $\begin{array}{c}\text { Group I } \\
(\mathbf{m m H g})\end{array}$ & $\begin{array}{c}\text { Group II } \\
(\mathbf{m m H g})\end{array}$ & $\begin{array}{c}\text { Multiple } \\
\text { Comparison Test }\end{array}$ \\
\hline $\begin{array}{c}\text { Pre Induction } \\
\text { (baseline) }\end{array}$ & - & - & - \\
\hline Post-induction & $-3.85(+/-8.17)$ & $-10.50(+/-7.83)$ & $\mathrm{P}=0.0012$ \\
\hline Post ECT & & & $\mathrm{P}<0.0001$ \\
\hline 1 minute & $46.00(+/-22.5)$ & $15.5(+/-18.98)$ & $\mathrm{P}<0.0001$ \\
\hline 2 minute & $39.50(+/-20.87)$ & $10.25(+/-14.93)$ & $\mathrm{P}<0.0001$ \\
\hline 3 minute & $29.75(+/-20.06)$ & $1.75(+/-11.96)$ & $\mathrm{P}<0.0001$ \\
\hline 4 minute & $21.25(+/-17.71)$ & $-5.25(+/-9.65)$ & $\mathrm{P}<0.0001$ \\
\hline 5 minute & $17.00(+/-18.56)$ & $-8.00(+/-8.23)$ & \\
\hline \multicolumn{2}{|c}{ Table 2: Mean Change In Systolic Blood Pressure } \\
\hline
\end{tabular}

Non-parametric ANOVA for repeated measures. ' $F$ ' value $=61.153, p<0.0001$ multiple comparison test, $p<0.0001$.

This analysis shows that there is a highly significant change $(\mathrm{p}<0.0001)$ in the systolic blood pressure post ECT between the two groups.

\begin{tabular}{|c|c|c|c|}
\hline & $\begin{array}{c}\text { Group I } \\
\text { (mmHg) }\end{array}$ & $\begin{array}{c}\text { Group II } \\
\text { (mmHg })\end{array}$ & $\begin{array}{c}\text { Multiple } \\
\text { Comparison Test }\end{array}$ \\
\hline Pre-induction (Baseline) & - & - & - \\
\hline Post induction & $-0.15(+/-5.80)$ & $-3.75(+/-6.28)$ & $\mathrm{P}<0.0001$ \\
\hline Post ECT & & & $\mathrm{P}<0.0001$ \\
\hline 1 minute & $26.25(+/-15.47)$ & $8.15(+/-11.96)$ & $\mathrm{P}<0.0001$ \\
\hline 2 minute & $22.50(+/-14.98)$ & $7.00(+/-11.37)$ & $\mathrm{P}<0.0001$ \\
\hline 3 minute & $16.00(+/-12.97)$ & $0.50(+/-9.04)$ & $\mathrm{P}<0.0001$ \\
\hline 4 minute & $11.06(+/-12.36)$ & $-6.50(+/-8.64)$ & $\mathrm{P}<0.0001$ \\
\hline 5 minute & $8.50(+/-11.22)$ & $-8.50(+/-9.21)$ & \\
\hline \multicolumn{4}{|l|}{ Table 3: Mean Change in Diastolic Blood Pressure } \\
\hline
\end{tabular}

Non parametric ANOVA for repeated measures ' $F$ ' value $=203.119, \mathrm{p}<0.0001$ Multiple comparison test, $\mathrm{p}<0.0001$. This analysis shows that there is a highly significant change $(\mathrm{p}<0.0001)$ in the diastolic blood pressure post ECT between the two groups.

\begin{tabular}{|c|c|c|c|}
\hline & $\begin{array}{c}\text { GROUP I } \\
\text { (beats /min ) }\end{array}$ & $\begin{array}{c}\text { GROUP II } \\
\text { (beats/min) }\end{array}$ & $\begin{array}{c}\text { Multiple } \\
\text { Comparison Test }\end{array}$ \\
\hline $\begin{array}{c}\text { Pre- induction } \\
\text { (baseline })\end{array}$ & - & - & - \\
\hline Post- induction & $7.40(+/-6.16)$ & $3.23(+/-7.71)$ & $\mathrm{P}<0.0001$ \\
\hline Post ECT & & & $\mathrm{P}<0.0001$ \\
\hline 1 minute & $30.27(+/-20.70)$ & $12.63(+/-15.72)$ & $\mathrm{P}<0.0001$ \\
\hline 2 minute & $26.35(+/-18.28)$ & $6.43(+/-16.44)$ & $\mathrm{P}<0.0001$ \\
\hline 3 minute & $19.85(+/-14.24)$ & $-1.28(+/-14.56)$ & $\mathrm{P}<0.0001$ \\
\hline 4 minute & $14.68(+/-14.10)$ & $-2.75(+/-13.2)$ & $\mathrm{P}<0.0001$ \\
\hline 5 minute & $11.20(+/-11.97)$ & $-4.65(+/-12.21)$ & \\
\hline \multicolumn{4}{|c}{ Table 4: Mean Change In The Heart Rate } \\
\hline
\end{tabular}


Non-parametric ANOVA for repeated measures ' $\mathrm{F}$ ' value $=150.4358, \mathrm{p}<0.0001$ Multiple comparison test, $\mathrm{p}<0.0001$.

This analysis shows that there is a highly significant change $(p<0.0001)$ in the heart rate post ECT between the two groups.

The differences between the two groups for duration of motor seizure, time for eye opening and time to follow simple commands were analysed using the students ' $\mathrm{T}$ ' test for paired observations.

SEIZURE DURATION: The seizure duration in the thiopentone-succinylcholine group was $45.4+/-13.20$ seconds while in the propofol-succinylcholine group it was $37.56+/-10.53$ seconds. The comparison between paired data indicated a difference of $7.84+/-15.64$ seconds, which was statistically significant $(\mathrm{p}<0.05)$.
TIME TO EYE OPENING: The time to eye opening in the thiopentone-succinylcholine group was 376.56+/-113.08 seconds, while in the propofol-succinylcholine group it was $331.32+/-106.26$ seconds. The comparison between paired data indicated a difference of $41.36+/-152.49$ seconds, which was not stastically significant.

RESPONSE TO SIMPLE COMMANDS: The time to response to simple commands in the thiopentone-succinylcholine group was $519.64+/-144.81$ seconds, while in the propofolsuccinylcholine group it was $442.16+/-126.07$ seconds. The comparison between paired data indicated a difference of $99.12+/-200.17$ seconds, which was statistically significant $(\mathrm{p}<0.05)$.

\begin{tabular}{|c|c|c|c|c|}
\hline \multirow{2}{*}{ Parameter } & \multicolumn{2}{|c|}{ Mean +/-S.D } & $\begin{array}{c}\text { Mean +/- S.D } \\
\text { of Difference } \\
\text { Between Paired Data }\end{array}$ & $\begin{array}{c}\text { Statistical } \\
\text { Significance }\end{array}$ \\
\hline & TS & PS & & Significant $\mathrm{p}<0.005$ \\
\hline Seizure duration (seconds) & $45.4+/-13.20$ & $37.56+/-10.53$ & $7.84+/-15.64$ & Not significant \\
\hline Time to eye opening & $376.56+/-113.08$ & $331.32+/-106.26$ & $41.36+/-152.49$ & Significant $p<0.05$ \\
\hline $\begin{array}{c}\text { Response to simple } \\
\text { commands }\end{array}$ & $519.64+/-144.81$ & $442.16+/-126.07$ & $92.12+/-200.17$ & \\
\hline \multicolumn{7}{|l|}{ Table 5: Intergroup Comparison of Seizure Duration, Time to Eye Opening and Response to Simple Commands. } \\
\hline
\end{tabular}

TS- thiopentone-succinylcholine group, PS-propofol-succinylcholine group

DISCUSSION: Historically, the goal of MECT has been to induce a generalized tonic-clonic seizure. ${ }^{4}$ For therapeutic response to occur, the seizure should be at least 20-30 seconds duration for a minimum aggregate of 210 seconds. However, the relationship between the therapeutic efficacy of MECT and cerebral seizure activity remains controversial. The median (Interquartile range) of seizure duration has been variously reported as 19(9) seconds and 23(9) seconds. The mean duration of seizure following the use of propofol was reported to be $17.9+/-2.5$ seconds. In our study, we found a mean seizure duration of $37.56+/-10.53$ seconds in the propofol group which, though longer than that reported in earlier studies is still significantly shorter $(p<0.05)$ than that seen in the thiopentone sodium group.

Methohexital is the most commonly used intravenous anaesthetic in MECT. Most of the studies to date have compared methohexital with propofol for seizure duration, haemodymanics and recovery profile. Propofol induction for MECT was shown to have shorter seizure duration.

Propofol was compared to thiopentone sodium as anaesthetic induction agent and heart rate, blood pressure, seizure response to MECT and recovery (As evaluated by time taken to open eyes on command and being able to sit unaided) were monitored. Patients were also asked to walk a distance of 10 metres unaided 20minutes after induction. Greater haemodynamic stability and shorter seizure times were noted with propofol. These patients also showed better quality of walking unaided after 20 minutes.

Our study compared 40 patients who were to undergo MECT. Blood pressure, heart rate, seizure duration, recovery (As determined by moving limbs to commands) were recorded. Our findings were comparable in that seizure duration was shorter, there was more stable haemodnyamics and faster psychomotor recovery in patients in whom anaesthesia was induced with propofol.

RECOVERY: In patients who are to undergo day-stay procedures (eg:- MECT), postictal confusion and even delirium may delay early return of cognitive function.5,6,7 Thus recovery profile may be in part related to the shorter duration of seizure activity. Propofol by its rapid induction, rapid termination of its hypnotic action and reduced postMECT seizure duration exhibits improved recovery profile. We found in our study that psychomotor recovery as judged by response to commands $(442.6+/-126.07$ seconds $)$ was significantly faster with propofol than with thiopentone sodium (519.64+/-144.81seconds).

CONCLUSION: On comparision of propofol with thiopentone sodium for induction in MECT motor seizure occurred with shorter duration for propofol and psychomotor recovery was significantly faster for propofol. Propofol also provided better haemodynamic stability. Emergence from anesthesia was similar in both the groups.

\section{BIBLIOGRAPHY:}

1. Leonora TF, Van Mourik GA, Utting JE. A comparison of the induction characteristics of thiopentone and propofol. Anaesthesia. 1985; 40:939-44.

2. Rolly G, Versichelen L. Comparison of propofol and thiopentone for induction of anaesthesia in premedicated patients. Anaesthesia. 1985;40:945-48. 
3. Simpson KH, Halsall PJ, Carr CME, Stewart KJ. Propofol reduces seizure duration in patients having anaesthesia for electroconvulsive therapy. British journal of Anaesthesia. 1988;61: 343-44.

4. Dwyer R, Lavery J, Mccarthy G, Dundee JW. Comparison of propofol and methohexitone as anaesthetic agents for electro convulsive therapy. Anaesthesia. 1988;43:459- 62.

5. Anthony JR, Richard MG, Catherine SS, John JD, Nicholas $\mathrm{CH}$, Michael AA. Comparison of methohexital and propofol for electroconvulsive therapy. Effects on haemodynamic responses and seizure duration. Indian J Anaesth 1989;70:412-17.
6. Rampton AJ, Griffin RM, Stuart CS, Abbot MA. Comparison of methohexital and propofol for electroconvulsive therapy: Effects on haemodynamic responses and seizure duration. Anaesthesiology 1989;70:412- 14.

7. Boey WK, Lai FO. Comparison of propofol and thiopentone as anaesthetic agents for electroconvulsive therapy. Indian J Anaesth. 1990;45:623-28. 